\title{
Vacuum plasma spraying of functionally graded tungsten/EUROFER97 coatings for fusion applications
}

\author{
R. Vaßen', K.-H. Rauwald', O. Guillon ${ }^{1,2}$, J. Aktaa ${ }^{3}$, T. Weber ${ }^{3}$, H. C. Back ${ }^{3}$, D. Qu ${ }^{3}$, \\ J. Gibmeier ${ }^{3}$ \\ ${ }^{1}$ Forschungszentrum Jülich, Institute of Energy and Climate Research (IEK-1), Jülich, \\ Germany \\ 2Jülich Aachen Research Alliance: JARA-Energy \\ ${ }^{3}$ Karlsruhe Institute of Technology, Institute for Applied Materials, Karlsruhe, \\ Germany
}

\begin{abstract}
As structural materials for future fusion power plants, reduced activation ferritic martensitic steels as EUROFER97 can be used. Unfortunately, the interaction of the plasma with the steel would result in a limited lifetime, so protective layers are investigated. An excellent protective material is tungsten, as it shows unique properties with respect to low sputtering, high melting points and low activation. However, the mismatch of thermo-physical properties between tungsten and EUROFER97 can lead to large stress levels and even failure.

A possible way to overcome this problem is the use of functionally graded material (FGM). The paper will describe the manufacture of these FGMs by vacuum plasma spraying and their characterization. First of all, two different feeding lines have been used to produce the coatings. A major problem lies in different melting points of tungsten and steel. So the particle size distribution has to be adjusted to achieve sufficient melting of both materials during the spray process. In a second step, the feeding rates were optimized to obtain the wanted amount of tungsten and steel phases in the graded structures. In a thermal spray process, the gradient cannot be made continuously, however it has to be applied in a step-wise manner. In this investigation, samples with 3 and 5 different concentrations (excluding the pure steel and tungsten part) have been produced. The microstructures of these layers have been investigated. In addition, hardness was measured and the residual stress state was determined by the hole drilling method.
\end{abstract}

\section{Introduction}

In a future fusion power plant of tokamak type the nuclear fusion reactions will occur inside torus shaped vacuum vessel in a very hot plasma in which the charged particles are confined by magnetic fields. The fast neutrons as the reaction product carrying the major part of the fusion energy are desired to leave the plasma and transfer their energy to the blanket which mainly consists of the plasma facing first wall (FW) and the tritium breeding units (BUs) behind. Despite the magnetic confinement heavy ions might escape the plasma at the edge and hit the FW causing its erosion due to physical and chemical sputtering, surface bubble formation and blistering [1]. Therefore the FW made out of EUROFER, a reduced activation ferritic martensitic (RAFM) steel, shall be protected by a sacrificial coating. As suitable material for the coating, tungsten is considered due to its crucial properties, i.e. particularly high melting point $\left(3422^{\circ} \mathrm{C}\right.$, [2]), low sputtering yield, high thermal conductivity, low activation and plasma compatibility.

Coating of a EUROFER component with a tungsten layer however would result in large residual stresses due to the large mismatch in the coefficient of thermal expansion (CTE) between these two materials (tungsten $4.410^{-6} / \mathrm{K}$, EUROFER 1.2 
$\left.10^{-5} / \mathrm{K},[3]\right)$. These stresses may cause failure of the coating systems either directly after processing or accelerate its failure during operation. To solve this problem the concept of functionally graded material (FGM) is adopted by introducing an interlayer between the tungsten coat and the EUROFER substrate made of graded tungsten/EUROFER material in which the composition of tungsten is gradually increased from $0 \%$ on the substrate side to $100 \%$ on the coat side $[2,4,5]$. Assuming that the mechanical properties are similarly graded according to the linear mixing rule, great potential of a sufficiently thick FG interlayer in reducing residual stresses could be determined by means of comprehensive finite element simulations $[6,7]$.

Different coating techniques have been discussed in the past to deposit thick tungsten coatings. One option is the use of magnetron sputtering [8], however, typically it leads to rather long processing times for obtaining coatings in the several hundred micrometer range. A suitable alternative is thermal spraying. In the past, it has been frequently demonstrated that thermal spraying is a suitable process for the deposition of tungsten coatings. The cheapest plasma spraying process is the atmospheric plasma spraying (APS, [9, 10]). However, due to the entrapment of air into the plasma plume a considerable oxygen up-take is difficult to avoid (e.g. 0.5 wt.\% in [11]). This can be reduced by using high velocity guns [12] or employing shroud gas during the deposition [13]. As a rather high oxygen up-take remains the most often used thermal spray process for the deposition of dense, high-quality tungsten coatings is vacuum plasma spraying (VPS, $[14,15,16,17])$. In this process the plasma gun is operated in a vacuum chamber which is evacuated and for the spraying refilled with an inert gas (e.g. Ar) atmosphere at chamber pressure of about 50 mbars. These conditions reduce the oxygen partial pressure and hence oxidation of the powderous feedstocks and also lead to a fast expanding plasma plume with high velocities of plasma gas and powders and thereby to high density coatings. Recently, it was demonstrated that the deposition of a $3 \mathrm{~mm}$ thick tungsten layer on a $50 \star 50 \mathrm{~mm}^{2}$ ferritic martensitic steel substrate is possible without spallation by careful control of the heating and cooling procedures. Also the hardness of the coatings was only about $10 \%$ less than the bulk value indicating a low porosity of the coating [18]. However, the problem of stresses induced by the large difference in thermal expansion coefficients between coating and substrate remain. As pointed out earlier a possible solution for this problem can be the introduction of graded interlayers, which largely reduce the maximum plastic deformation in the region close to the interface and by that reduce the risk of coating damage [3, 19]. Such graded structures can be, at least on a scale corresponding to the size of the used feedstock materials, produced by thermal spray processes. For the tungsten/copper system this has been shown in [20]. In [21] tungsten/steel results with one mixed interlayer and porosity levels of $20 \%$ are shown. No details on the processing conditions are given. In addition, as pointed out in the theoretical studies a more extended region as in a 3 or 5 step gradient can effectively reduce the localized deformation due the thermal expansion mismatch and will expect improved lifetimes especially in highly dense structures as deposited in the here presented approach.

For a tungsten/steel system, first results on such a microstructure have been reported in [22]. Initial thermal cycling experiments demonstrated the feasibility of the concept. The present paper will now focus on the manufacturing process and the methods to optimize graded layers by VPS. In addition, selected results of microstructural and chemical composition analyses as well as nano- and micro- 
hardness measurements are presented, demonstrating the quality of the sprayed graded layers and, hence, the success of the pursued optimization approach.

Knowledge about process-induced residual stresses is essential to assess the mechanical integrity of graded parts processed by means of VPS. In the present case of a tungsten/steel system the graded layer covers a rather large range with the final tungsten layer with a thickness of about $500 \mu \mathrm{m}$. The large depth range from this top layer down to the substrate that might span $>1 \mathrm{~mm}$ must be considered by the residual stress analysis method. In a non-destructive way, only the very surface (only some $\mu \mathrm{m}$ ) is accessible using conventionally generated soft lab X-rays. Residual stress for inhomogeneous, hence graded material states, can only be determined non-destructively by means of high energy synchrotron X-ray diffraction and neutron diffraction. Both probing methods are only usable at large scale facilities, thus the access is strongly limited. Furthermore, the depth range for tungsten is limited since tungsten is a strongly absorbing material in regard to X-rays even for high energy $\mathrm{X}$ rays.

To provide a less restrictive analysis approach mechanical residual stress analysis techniques are appropriate. The most widely used mechanical method for determination of residual stress depth distributions is the incremental hole drilling method. Since the elastic properties, which are essential for calculating residual stresses from local strain relaxations measured at the top surface during stepwise drilling a blind hole, vary with depth from graded material states, this must be considered during calibration of the method. For layered material states, the limitations of the application of the conventional incremental hole drilling approach were already studied [23, 24] and a measuring and evaluation approach was proposed [25]. This approach is based on the case sensitive calibration by taking into account the local variation of the elastic properties of the layered material state. Here, this approach will be adapted for continuously graded structures. By this means, residual stress depth distributions can be determined up to depths of about $1.2 \mathrm{~mm}$.

\section{Experimental}

For the initial trials during the development phase small tungsten substrates $(10 \mathrm{~mm}$ diameter) have been used. For the graded coatings the substrate material used was a EUROFER97 (a reduced activation ferritic-martensitic $9 \% \mathrm{Cr}$ steel with $1 \% \mathrm{~W}$ and $0.11 \% \mathrm{C}$ ) with a size of $100 * 100 * 18 \mathrm{~mm}^{3}$. The same material was used as powder to produce the graded coatings. It was produced by gas atomization and supplied by Karlsruhe institute of technology (KIT). For the first trials a powder with a rather broad volumetric particle size distribution (Fig. 1a), measured using static light scattering with the Horiba LA 950, was used. Further experiments have been made with a sieve fraction below $57 \mu \mathrm{m}$ showing a particle size distribution avoiding large particles in the $100 \mu \mathrm{m}$ range (Fig. 1b). For the final deposition of the graded coatings the below $57 \mu \mathrm{m}$ sieve fraction of a EUROFER97 powder by NANOVAL GmbH \& Co, Berlin, Germany, was taken. The mean particle size was $22 \mu \mathrm{m}$. For the tungsten deposition a powder (Amperit 140.067) from HC-Starck, Laufenburg, Germany, with a mean particle size of about $10 \mu \mathrm{m}$ was used for the first trials. Due to its poor flowability a larger powder with a mean particle size of $17 \mu \mathrm{m}$ was used for subsequent trials (AW3105A1, Eurotungstene, France, Fig. 1c). These different particle sizes have been taken to compensate the huge difference in the melting point of both materials (EUROFER97 about $1500^{\circ} \mathrm{C}$, tungsten $3422^{\circ} \mathrm{C}$ ) and hence allow the proper melting 
of both materials in one plasma plume. The two used powder configurations are summarized in Table 2.

Spraying has been performed in a Multicoat vacuum plasma spraying system manufactured by Oerlikon Metco, Wohlen Switzerland, employing a F4 torch. The coating is deposited by a meander type deposition scheme with a step size of $4 \mathrm{~mm}$. The major processing conditions are listed in Table 1 for the different trials.

The feeding rates are given in percentage of the maximal rotation speed of the feeder. The corresponding feeding rate in $\mathrm{g} / \mathrm{min}$ have been measured for $10 \%$ to be for the EUROFER97 $(<57 \mu \mathrm{m}) 28 \mathrm{~g} / \mathrm{min}$ and for the tungsten (Eurotungstene) 55 $\mathrm{g} / \mathrm{min}$.

Based on the results of the spraying with an injection of steel and tungsten powder at constant feeding, the needed feeding rates and number of passes for each zone in the graded coatings have been calculated. The envisaged type of grading is summarized in Table 3. As the number of passes is an integer and as the feeding should not differ too much from the tested feeding rates, the actual thickness of each layer in the graded zone might differ from the values in Table 3.

For characterization the coatings have been cut, embedded, ground and polished. Analyses of the microstructure were performed by light and scanning electron microscopy (SEM). The true chemical compositions of the different layers within the graded zone were determined using the energy dispersive X-ray spectroscopy (EDS) analysis provided by the SEM and compared with the nominal ones. In addition, Berkovich nano- as well as Vickers micro-hardness in the graded zone are measured using G200 (Agilent Technologies, at 1800-2000 nm depth) and Zwick Hardness Tester $(9.8 \mathrm{~N})$.

Local values for the local elastic properties of the graded material have to be determined as input for the finite element simulations carried out for the proper calibration of the incremental hole drilling method. These values were measured by means of an instrumented micro-hardness testing.

Residual stress analysis was carried out by means of incremental hole drilling using a milling guide of type RS200 from Vishay Measurements Group (US) and tapered TiN coated endmills with a nominal diameter of $\varnothing 1.6 \mathrm{~mm}$. The strain relaxations were measured during stepwise drilling by means of strain gage rosettes of type CEA-06062UM-120 from Vishay Measurements Group (US). Each strain gage was lined in a Wheatstone half bridge with temperature compensation using the five-wire-system. For calculation of the residual stresses, calibration functions were calculated by means of the finite element method (FEM) for the differential approach formulated in [26] according to the procedure described in [25]. Here, the local elastic properties registered by means of instrumented indentation were considered as input data, hence for each graded coating system (see also Table 3) specific case sensitive calibration functions were determined.

\section{Results and discussion}

\section{Manufacture}

Fig. 2 shows the microstructure of a coating sprayed with condition 1 in Table 1 . For the first experiments, tungsten substrates were used. Obviously a dense coating could be obtained with the dark phase being the EUROFER97 phase. The feeding 
was adjusted so that a composition of 50\% tungsten and 50\% EUROFER97 should be produced corresponding to preliminary experiments. In fact, image analysis revealed a composition of $60 \%$ tungsten and 40\% EUROFER97.

It is also obvious that the coating shows an extremely layered structure and that several large, not properly molten steel particles are found. The incomplete melting was thought to be an outcome of the rather broad particle size distribution of the EUROFER97 powder (see Fig. 1a). This was reduced by only using a sieve fraction below $57 \mu \mathrm{m}$ for the further experiments (see Fig. 1b). As can be seen in the following results, this measure led to a considerable improvement.

A more difficult issue was the distinct layering of the coating. The first experiments have been performed with a F4 torch with a nozzle with a diameter of $7 \mathrm{~mm}$ using two internal injectors one from the bottom for tungsten and one from the top for the EUROFER97 powder. Assuming simplifying that each powder is characterized by one trajectory within the plume, the stand-off distance has to be at the location, where these trajectories meet, to avoid layering. In front of and behind this point the foot prints of the trajectories will separate quite fast which will result in a layered coating. A possible way to reduce that is the use of an injection from the same side (in our case from the bottom) for both powders. The configuration used showed a $45^{\circ}$ angle between the injectors, the nozzle diameter in this new configuration was slightly larger $(8 \mathrm{~mm})$. Unfortunately, the new nozzle did not contain an electrode for discharge cleaning anymore, however no interface contamination have been detected.

As the spraying conditions had to be adopted to the new nozzle configuration a rather different process parameter set was used in the new approach which had been shown good results for other type of metallic coatings (s. Table 1, \#2). Due to the larger nozzle, the gas flow was slightly increased. Also the plasma power was increased, approaching the limit of the F4 torch to improve the melting of the particles. In order to reduce the thermal load of the substrates, the stand-off distance had to be increased. Still the substrate temperatures are higher (about $750^{\circ} \mathrm{C}$ compared to $600^{\circ} \mathrm{C}$, s. Table 1). This higher substrate temperature will promote the formation of a dense coating microstructure, however, might be an issue due to a thermal degradation of the substrate.

The spraying of a graded structure implies the knowledge of the deposition efficiency for different compositions. In order to obtain these data, experiments with different feeding rates have been performed. The resulting microstructures can be seen in Fig. 3. Also here tungsten substrates have been used. The layering is significantly reduced, however still some large, only slightly deformed EUROFER097 particles, can be found.

In Fig.4a the corresponding amount of W-phase for the three coatings in Fig. 3 determined by image analysis is plotted as a function of the $\mathrm{W}$-feeding rate divided by the sum of $W$-feeding plus EuroFer feeding rates. Obviously, there is no linear behavior. At $50 \% \mathrm{~W}$-feeding rate also $50 \%$ of $\mathrm{W}$-phase is observed in the coating. However, the amount of tungsten is reduced for both low and high feeding rates. Also the deposition efficiency is reduced for both low and high feeding rates (see Fig. 4b). In this figure the total thickness of the coating $(0.85$ to $1.06 \mathrm{~mm})$ divided by the sum of the feeding rates in percent (10 to $14 \%$ used) at the constant gun velocity of 440 $\mathrm{mm} / \mathrm{s}$ is taken as a measure of the deposition efficiency. This might be explained by a loading effect which leads to reduced plasma temperatures and hence reduced heat transfer for the experiments with one powder showing rather high feeding rates. However, that cannot explain the reduced W-amount in the case of small W-feeding rates (Fig. 4a). Looking at the micrographs in Fig. 3c one can see that the amount of 
rather spherical, hardly deformed EUROFER97 particles (dark features) is very large for these conditions. Probably the bonding of W-splats to such surfaces is rather limited and that might explain the reduced $\mathrm{W}$-content.

The data shown in Fig. 4 have been used to calculate the feeding rates for the deposition of graded coatings according to Table 3.

By image analysis also the porosity levels of the deposited layers have been determined. It is between 1 and $2 \%$ for the graded layers and about 3\% for the pure tungsten coating.

\section{Residual stress evaluation}

In Fig. $5 \mathrm{a}-\mathrm{e}$ the residual stress depth distributions for sample types $\mathrm{A}-\mathrm{E}$ (see also Table 3) are shown in comparison to the Young's modulus distribution considered for calculation of the calibration functions for the incremental hole drilling method. Since for all samples studied here, the strain relaxations measured in three definite directions are almost the same, which indicates that the residual stress distribution induced by plasma spraying is almost equi-biaxial, only the average values are presented. The residual stress distributions were slightly smoothened after stress evaluation by using cubic spline functions. For all measured samples a decrease of the stress level is observed at the surface of the coatings. It is assumed that this is related to the roughness of the coatings and an uncertainty in the determination of the location of the coating surface. In the roughness peaks the compressive stress levels can relax which leads to lower measured residual stress levels at the surface.

For all graded coatings under study, compressive residual stresses were determined. As discussed above at the very surface lower compressive residual stress were found that range between approx. $-360 \mathrm{MPa}$ (type E) and $-755 \mathrm{MPa}$ (type C). For higher depth the compressive residual stress rapidly increases to rather high values, which reach about $-1500 \mathrm{MPa}$ (type $\mathrm{D}$ and $E$ ) or even higher (type $A-C$ ). The highest values were determined for graded coating type A with about -1850 MPa in a depth of about $0.16 \mathrm{~mm}$. The residual stress distributions of graded coating type A $C$ show a maximum below the surface (type $A: 0.16 \mathrm{~mm}, B: 0.26 \mathrm{~mm}, C: 0.26 \mathrm{~mm}$ ). For coating type $D$ and $E$ the residual stress distribution more likely exhibit a plateau value even for higher depth ranging slightly below compressive residual stresses of about $-1500 \mathrm{MPa}$.

In the following, these stress levels will be compared with values obtained from elastic estimations. In thermal spray coatings typically tensile quenching stresses $\sigma_{\text {quench }}$ are found due to the fast cooling of the splats to the substrate temperature (about $750^{\circ} \mathrm{C}$, see Table 1). An upper limit for this stress can be estimated by [27]

$$
\sigma_{\text {quench }}=\frac{\mathrm{E}_{\text {coating }} \alpha_{\text {coating }}\left(T_{m}-750^{\circ} \mathrm{C}\right)}{1-v},
$$

with $\mathrm{E}_{\text {coating }}$ being the Young's modulus of the coating and acoating being the coefficient of thermal expansion (CTE) of the coating, respectively. Taking as Young's modulus and Poisson number of tungsten $\mathrm{E}_{\text {coating }} \approx 300 \mathrm{GPa}$ (see Fig. 5) and $v=0.28$ and $\mathrm{Tm}$ the melting point of tungsten $\left(3422^{\circ} \mathrm{C}\right)$ an extremely high tensile stress value of 4.9 $\mathrm{GPa}$ follows. Measurements of these quenching stresses in thermally sprayed coatings typically show much lower values (about an order of magnitude lower, $[26,28])$ due to high temperature relaxation processes.

An additional cooling stress will develop during cooling of the substrate to room temperature [27]. A simple estimation of this stress level assuming again purely elastic material behavior can be done for thin coatings by the following formula 


$$
\sigma_{\text {cooling }}=\frac{\mathrm{E}_{\text {coating }} \Delta \alpha \Delta T}{1-v}
$$

with $\Delta \alpha$ the difference in thermal expansion coefficients $\left(7.610^{-6} / \mathrm{K}\right.$, see CTEs given earlier) and $\Delta \mathrm{T}$ the temperature change ( $730 \mathrm{~K}$, see Table 1 ) a compressive cooling stress of $2.3 \mathrm{GPa}$ can be estimated.

Assuming that the tensile quenching stress is roughly one tenth of the upper limit given above (so about $0.5 \mathrm{GPa}$ ) a residual stress of about $1.8 \mathrm{GPa}$ would be the consequence. This value is in rather good agreement with the stress levels obtained by the incremental hole drilling method. Obviously, this residual stress level is very high and with that the stored elastic energy which can promote delamination of the rather thick tungsten coatings. As pointed out earlier, the used approach of graduation of the interface can significantly reduce localized deformation and hence degradation of near-interface regions and by that reduce the risk of failure of the coatings [18].

\section{Microstructure and hardness profiles}

As shown in Fig. 6 the cross-sectional SEM micrographs reveal that stepwise gradation is successfully formed between tungsten coating and EUROFER substrate and there are no obvious interfaces among FG-interlayers, especially for coating with five FG-interlayers which has finer gradation. In addition, no delamination is observed for both coatings, neither at the interface between substrate and coating nor at the supposed interfaces between the different layers of the coating.

The light microscope and SEM micrographs were in addition used to measure the actual total thickness of the graded zone. The values obtained are listed in comparison to the nominal ones in Table 3. For all produced graded coatings the nominal thicknesses are overshot. This can be adjusted by slight reduction of the feeding rates. With regard to the reduction of residual stresses, the observed larger thickness of the graded layer can even be beneficial. Furthermore, Table 3 shows that the difference increases with increased nominal thickness and larger number of layers of the graded zone.

In Fig. 7 the concentrations of tungsten in the different layers of the graded zone as measured by EDS for the specimen with 5 layers as FG interlayer are plotted in comparison to the nominal ones. It can be noticed that the values are slightly lower than the nominal ones except for the layer with the nominal concentration of $63 \%$ where the true value is slightly higher. However, the concentration of tungsten follows a globally linear gradient as desired.

The nano- and micro-hardness measurements verify the successful manufacturing of the graded interlayer in particular and the pursued approach in general (see Fig. $4 a$ and $4 \mathrm{~b}$ ). The mean values within the graded zone follow the nominal concentration of tungsten, as it is plotted as an example in Fig. $8 \mathrm{a}$ and $8 \mathrm{~b}$ for the graded zone with 3 layers. Fig. $8 \mathrm{~b}$ shows the Vickers micro-hardness values measured in different specimens cut from the manufactured plate in two different orientations. The noticeable similarity indicates the overall good quality of the manufactured coating system. However, the Berkovich nano-hardness measured in the EUROFER substrate in the vicinity of the interface is remarkably lower than that measured far from the interface (red marker in Fig. 8a) which coincides well with that of EUROFER in the as-received state. This suggests that during the deposition of the first layer the substrate undesirably altered over a certain distance from the interface what needs to 
be avoided by further optimization of the VPS parameters. The standard deviation of the hardness values of the nano-hardness measurement is as a result of the more local measurement larger than for the Vickers micro-hardness data. This corresponds to the microstructure build up from particles of micrometer size.

\section{Conclusion}

The manufacture of protective dense tungsten layers on EUROFER97 structural materials for a future fusion reactor is possible via vacuum plasma spraying (VPS). It could be shown that this technique also allows the production of graded structures of tungsten and steel which reduce the localized deformation at the interface as a result of the large mismatch in thermal expansion coefficients between tungsten and EUROFER97. The huge difference in the melting point of tungsten and steel could be compensated in the thermal spray process by adjusting particle sizes and injection conditions. Different types of graduation could be produced, the measured microstructural and mechanical properties were in good accordance with the envisaged profiles.

In addition, it was demonstrated that stress profiles could be determined by the incremental hole drilling method. These results showed a gradient in the residual stress levels throughout the graded zones up to the rather high compressive residual stress level in the final tungsten coating.

\section{Acknowledgement}

Part of this work has been carried out within the framework of the EUROfusion Consortium and has received funding from the Euratom research and training programme 2014-2018 under grant agreement No 633053. The views and opinions expressed herein do not necessarily reflect those of the European Commission. The authors also gratefully acknowledge the German Research Foundation (DGF) for additional funding of the work (VA163/6-2). 


\section{Literature:}

1 K. Ehrlich, The development of structural materials for fusion reactors. Philosophical Transactions of the Royal Society A: Mathematical, Physical and Engineering Sciences 357(1999) 595-623.

2 J. E. Emsley, The Elements, 2nd ed., Oxford University, New York, 1991.

3 T. Weber, J. Aktaa, Numerical assessment of functionally graded tungsten/steel joints for divertor applications, Fusion Engineering and Design 86 (2011) 220-226.

4 J. Aktaa, W.W. Basuki, T. Weber, P. Norajitra, W. Krauss, J. Konys, Manufacturing and joining technologies for helium cooled divertors, Fusion Engineering and Design, 89 (2014) 913-920.

5 D.D. Qu, Development of functionally graded tungsten/EUROFER97 coating systems, PhD Thesis, Karlsruhe Institute of Technology, 2016.

6 D.D. Qu, W.W. Basuki, J. Aktaa, Numerical assessment of functionally graded tungsten/steel coating system for first wall applications, Fusion Engineering and Design 98-99 (2015) 1389-1393.

7 D. D. Qu, W. W. Basuki, J. Gibmeier, R. Vaßen, J. Aktaa, Development of functionally graded tungsten/EUROFER coating system for first wall application, Fusion Science and Technology, 68 (2015): 578-581.

8 C. Ruset, E. Grigore, H. Maier, R. Neu, H. Greuner, M. Mayer, G. Matthews, Development of W coatings for fusion applications, Fusion Engineering and Design 86 (2011) 1677-1680.

9 F. Wang, J. Huang, Transient high heat load performance of atmospheric plasma sprayed tungsten coating, Journal of Fusion Energy 35 (2016) 608-612.

10 O. Kovářík, P.Haušild, J. Siegl, T. Chráska, J.Matějiček, Z. Pala, M. Boulos, The influence of substrate temperature on properties of APS and VPS W coatings, Surface \& Coatings Technology 268 (2015) 7-14.

$11 \mathrm{~F}$. Wang, J. Huang, Performance characterization and improvement of tungsten coating atmospheric plasma sprayed with submicron powder, Surface \& Coatings Technology 254 (2014) 61-64.

12 J. Huang, F Wang, Y. Liu, S. Jiang, X. Wang, B. Qi, L. Gao, Properties of tungsten coating deposited onto copper by high-speed atmospheric plasma spraying, Journal of Nuclear Materials 414 (2011) 8-11.

13 J. Matejıcek, T. Kavka, G. Bertolissi, P. Ctibor, M. Vilemova, R. Musalek, and B. Nevrla, The role of spraying parameters and inert gas shrouding in hybrid water-argon plasma spraying of tungsten and copper for nuclear fusion applications, Journal of Thermal Spray Technology 22, 5 (2013)744755.

14 D. J. Varacalle, Jr., L. B. Lundberg, M. G. Jacox, J. R. Hartenstine, W. L. Riggs, H. Herman and G. A. Bancke, Fabrication of tungsten coatings and monoliths using the vacuum plasma spray process, Surface and Coatings Technology, 61(1993) 79-85.

15 X. Jiang, F. Gitzhofer, M.I. Boulos, Thermal spray coating of tungsten for tokamak device, Plasma Science \& Technology, Vol.8, No.2, Mar. 2006.

16 F. Chong, J. Chen, J. Li, X. Zheng, C. Ding, Thermal performance study of VPS-W coatings on CuCrZr under high heat flux, Plasma Science and Technology, Vol.9, No.3, Jun. 2007.

17 T.Tokunaga, H. Watanabe, N.Yoshida, T. Nagasaka, R. Kasada, Y.-J. Lee, A. Kimura, M. Tokitani, M. Mitsuhara, T. Hinoki, H. Nakashima, S. Masuzaki, T.i Takabatake, N. Kuroki, K. Ezato, S. Suzuki, M. Akiba, Development of high-grade VPS-tungsten coatings on F82H reduced activation steel, Journal of Nuclear Materials 442 (2013) S287-S291.

18 S. Y. Moon, C.H. Choi, H. S. Kima, P. Oha, B. G. Honga, S. K. Kim, D. W. Lee, Thick tungsten coating on ferritic-martensitic steel applied with a vacuum plasma spray coating method, Surface \& Coatings Technology 280 (2015) 225-231.

19 T. Weber, M. Härtelt, J. Aktaa, Considering brittleness of tungsten in failure analysis of heliumcooled divertor components with functionally graded tungsten/EUROFER97 joints, Engineering Fracture Mechanics 100 (2013) 63-75.

20 J.-E. Döring, R. Vaßen, G. Pintsuk, D. Stöver, The processing of vacuum plasma-sprayed tungsten-copper composite coatings for high heat flux components, Fusion Engineering and Design 66/68 (2003) 259-263.

21 H. Greuner, H.Bolt, B.Böswirth, S.Lindig, W.Kühnlein, T.Huber, K.Sato, S.Suzuki Vacuum plasmasprayed tungsten on EUROFER and 316L: Results of characterisation and thermal loading tests, Fusion Engineering and Design 75 (2005) 333.

22 T. Weber, M. Stüber, S. Ulrich, R. Vaßen, W.W. Basuki, J. Lohmiller, W. Sittel, J. Aktaa, Functionally graded vacuum plasma sprayed and magnetron sputtered tungsten/EUROFER97 
interlayers for joints in helium-cooled divertor components, Journal of Nuclear Materials 436 (2013) 29-39.

$23 \mathrm{E}$. Obelode, J. Gibmeier, Residual stress analysis on thick film systems by the incremental holedrilling method - simulation and experimental results, Experimental Mechanics 53 (2013) 965 976.

24 E. Held, J. Gibmeier, Residual stress analysis of thick film systems by the incremental hole-drilling method - influence of interlayers and interfacial roughness, HTM Journal of Heat Treatment and Materials 69 (2014) 71-79.

$25 \mathrm{E}$. Held, J. Gibmeier, Application of the incremental hole-drilling method on thick film systems - an approximate evaluation approach, Experimental Mechanics 55 (2015) 499-507.

26 T. Schwarz, H. Kockelmann, Die Bohrlochmethode - ein für viele Anwendungsbereiche optimales Verfahren zur experimentellen Ermittlung von Eigenspannungen, Messtechnische Briefe, Bd. 29 (1993) 33-38.

27 S. Kuroda, T.W. Clyne, The quenching stress in thermally sprayed coatings, Thin Solid Films, 200 (1991) 49-66.

28 T. Keller, N. Margadant, T. Pirling, M. J. Riegert-Escribano, W. Wagner, Residual stress determination in thermally sprayed metallic deposits by neutron diffraction, Materials Science and Engineering A 373 (2004) 33-44. 